Pasado y Memoria

ISSN: 2386-4745

Núm. 23, 2021, pp. 283-306

https://doi.org/10.14198/PASADO2021.23.12

Estudios

\title{
Política, Iglesia y dictadura en Argentina. El Partido Demócrata Cristiano durante la denominada Revolución Libertadora. (Corrientes, 1955-1958)
}

\section{Politics, Church and Dictatorship in Argentina. The Christian Democratic Party during the Revolución Libertadora. (Corrientes, 1955-1958)}

\author{
María del Mar Solís Carnicer \\ Universidad Nacional del Nordeste/CONICET, Argentina \\ marimarsolis@yahoo.com.ar \\ https://orcid.org/0000-0002-5065-3611 \\ Mayra Soledad Maggio \\ Universidad Nacional del Nordeste/CONICET, Argentina \\ mayitamaggio@hotmail.com \\ https://orcid.org/0000-0002-0305-3701
}

Recibido: 18/12/2020

Aceptado: 14/04/2021

Cómo citar este artículo: SOLÍS CARNICER, María del Mar, MAGGIO, Mayra Soledad (2021). Política, Iglesia y dictadura en Argentina. El Partido Demócrata Cristiano durante la denominada Revolución Libertadora. (Corrientes, 1955-1958). Pasado y Memoria. Revista de Historia Contemporánea, (23), pp. 283-306, https:// doi.org/10.14198/PASADO2021.23.12

\section{Resumen}

En 1955, un golpe de Estado liderado por las Fuerzas Armadas en Argentina provocó la caída del presidente Juan Domingo Perón poniendo fin a casi una década de gobierno. Aunque la Iglesia Católica había manifestado su apoyo inicial al peronismo, ya se había constituido hacía tiempo en una aliada clave de la oposición. Su implicación no

C2021 María del Mar Solís Carnicer y Mayra Soledad Maggio 
se limitó al golpe de Estado, sino que continuó durante la dictadura surgida del mismo, proceso que se autodenominó Revolución Libertadora. El presente trabajo aborda el estudio de algunos aspectos de la relación entre la Iglesia y la Política durante ese período, desde un ámbito acotado como la provincia de Corrientes, situada en el nordeste de Argentina, con rasgos políticos y sociales tradicionales y con una fuerte religiosidad. Se centra para ello en el análisis de la organización del Partido Demócrata Cristiano, su ideario, y su actuación política en los primeros años de su formación.

Palabras clave: Iglesia; Política; Dictadura; Partido Demócrata Cristiano; Corrientes.

\begin{abstract}
In 1955, a coup-d'état led by the Armed Forces in Argentina caused the fall of President Juan Domingo Perón, thus putting an end to almost a decade of government. Despite having shown initial support for Peronism, the Catholic Church had long before become a key ally of the opposition. Its involvement was not restricted to the coup, and continued during the resulting dictatorship. The process was called Liberation Revolution. This paper sets as its aim to study some aspects of the relationship between Church and Politics during that period, focusing on the limited area of the province of Corrientes, located in the northeast of Argentina, boasting both traditional politi$\mathrm{cal} /$ social features and strong religious committment. The focus is on analysis of the organization of the Christian Democratic Party, its ideology and political performance in the first years of its formation.
\end{abstract}

Keywords: Church; Politics; Dictatorship; Christian Democratic Party; Corrientes.

\title{
Introducción
}

La caída del peronismo y el triunfo de la autodenominada Revolución Libertadora en septiembre de 1955 marcó el inicio de un período de gran inestabilidad política y de conflictividad social que se extendería durante al menos las dos siguientes décadas en Argentina. En líneas generales, el arribo de la dictadura significó una profunda reformulación del espacio político nacional ya que se intervinieron los gobiernos de todas las provincias y se dio nuevamente lugar a las expresiones de los sectores antiperonistas que habían visto limitadas considerablemente su capacidad de acción en los últimos años. La inestabilidad política y la conflictividad social fue producto fundamentalmente de la exclusión del Partido Peronista -expresión política mayoritaria-, de la debilidad mostrada por los partidos políticos opositores para recomponer el orden político y de la injerencia permanente de las Fuerzas Armadas en los asuntos públicos. Además, el universo simbólico que acompañó el rumbo del nuevo gobierno se reflejó en la elección de muchos de sus integrantes, marcados por un profundo nacionalismo y clericalismo (Tcach, 2003). 
La dictadura que se instaló en el gobierno en 1955 tras el golpe se extendió hasta mayo de 1958, luego de que las elecciones generales del 23 de febrero del mismo año consagrasen presidente a Arturo Frondizi, candidato de la Unión Cívica Radical Intransigente (UCRI) (Spinelli, 2005). En cada una de las provincias el escenario político se adaptó a los nuevos tiempos y Corrientes, situada en el nordeste de Argentina, no fue la excepción. Caracterizada por poseer rasgos sociales tradicionales y una fuerte religiosidad, su situación política se asentaba en la presencia de dos partidos provinciales tradicionales de corte conservador: el liberal y el autonomista que la habían gobernado en forma ininterrumpida desde fines del siglo XIX hasta 1946 mientras que la Unión Cívica Radical -partido de carácter nacional que también actuaba en la provincia- sólo había adquirido cierta relevancia en los últimos años.

Este trabajo se sitúa en una perspectiva que busca analizar algunos procesos políticos nacionales a partir de una escala más reducida, la provincial. Los estudios regionales/provinciales/locales han adquirido un fuerte impulso en los últimos años en la historiografía argentina permitiendo aportar matices y nuevos problemas a aquellos trabajos situados en una escala nacional pero fundamentalmente centrados en la ciudad de Buenos Aires y su zona de influencia, muchas veces generalizando sus conclusiones a todo el territorio sin tener en cuenta las enormes diferencias regionales. ${ }^{1}$ La dinámica de estos estudios en nuestro país -a diferencia de otros espacios de América Latina- comenzó a gozar de legitimación recién en estos últimos años, gracias a la participación y

1. La etapa de la Revolución Libertadora ha sido abordada a nivel subnacional en los últimos años, pero son aún escasas las contribuciones en este sentido. Sin embargo, merece citarse el pionero trabajo de Tcach (1994). Además, se han publicado varios dossiers en revistas científicas destacándose « $40 .^{\circ}$ aniversario de la «Revolución Libertadora» que se publicó en Estudios en 1996, en el que participaron entre otros Ricardo Sidicaro, Lucio Garzón Maceda y Luis Alberto Romero, y «La Revolución Libertadora en espacios regionales: actores, prácticas y discursos», publicado en el N. ${ }^{\circ} 16$ de la revista Páginas de la Escuela de Historia de la Universidad de Rosario en el año 2016. Este último, coordinado por Fernando Aníbal Castillo reúne los trabajos de Yamile Álvarez «Aportes para una historia de la Revolución Libertadora en Mendoza»; Silvana Ferreyra «Junta Consultiva y Comisiones Investigadoras en la Provincia de Buenos Aires: usos de la escala para pensar el conflicto peronismo-antiperonismo»; Leandro Lichtmajer « ¿Una crisis de crecimiento? La expansión de la Unión Cívica Radical de Tucumán durante la «Revolución Libertadora»; Marta Ruffini «Tiempos antiperonistas en la Patagonia argentina. La acción de las Comisiones Investigadoras durante la «Revolución Libertadora» y de Fernando Castillo «La represión antiperonista y su justificación en Jujuy en tiempos de la Revolución Libertadora». Para el caso de Salta podemos citar la ponencia de Rubén Correa y Sergio Quintana «El juego imposible»: proscripción, neoperonismo y debilidad del sistema de partidos en Salta, 1958-1966» presentada en el Cuarto Congreso uruguayo de Ciencias Políticas, en Montevideo del 14 al 16 de noviembre de 2012. 
producción impulsada desde grupos de investigación localizados en distintas unidades académicas, y si bien el marco «nacional» aún parece eclipsar la sistemática producción de corte regional y local, ésta no deja de ser una referencia que se ha transformado paulatinamente (Fernández, 2007).

En este artículo -que constituye una primera aproximación al tema-indagamos, por un lado, los vínculos existentes entre el poder político y la Iglesia Católica y las dimensiones discursivas y simbólicas que adquirió esa relación durante el período previo al golpe de Estado de 1955 y en el gobierno dictatorial posterior. Además, examinamos las formas de participación política que ensayó el catolicismo correntino en el marco de un proceso de expansión de la presencia institucionalizada de los partidos confesionales católicos en Argentina. Nuestro interés estará focalizado en analizar el derrotero del Partido Demócrata Cristiano (PDC) en Corrientes, los itinerarios de su organización, las estrategias que sostuvieron para su supervivencia y consolidación y las diferentes representaciones en el marco del gobierno de facto y frente a la reapertura democrática.

En cuanto a las fuentes utilizadas recurrimos fundamentalmente a la prensa local, sobre la cual sostuvimos la reconstrucción histórica² ${ }^{2}$ Las escasas posibilidades de acceso a las fuentes producidas por el PDC correntino, reorientó la consulta al periódico $\mathrm{El} \mathrm{Liberal}^{3}$. La prensa escrita fue un elemento fundamental

2. La hemeroteca del Archivo General de la Provincia de Corrientes resguarda los ejemplares de los periódicos correntinos. Salvo algunas excepciones en que se encuentran encuadernados, la mayoría de ellos se encuentran en un estado precario de conservación, lo que dificulta su consulta.

3. El Liberal comenzó a publicarse en la ciudad de Corrientes el 19 de marzo de 1909, como representante del partido del mismo nombre. Pasó luego por un período independiente entre 1916 y 1918, para después transformarse, aunque sin reconocerlo abiertamente, en representante del partido Autonomista. En 1916, el periódico fue vendido y asumió como nuevo director Servando Lubary Medina, quien estuvo al frente del medio hasta enero de 1918. En este período, adquirió un carácter de «diario independiente». Entre 1918 y 1921, asumió la dirección del diario Hernán Gómez, sumando varios colaboradores que dieron impulso al diario desde el punto de vista periodístico y técnico. En este período el diario abandonó un tanto el tono «independiente» que había conseguido en la etapa anterior, demostrándose con mayor claridad su vínculo con el partido Autonomista. Tras el golpe de Estado de 1943 el periódico fue víctima de persecuciones y censura. Posteriormente, el comercio le fue retaceando los avisos publicitarios y al no poder sostenerlo pasó por varias manos hasta que en 1952 fue alquilado por el empresario de medios, Enrique Jasid, muy vinculado al gobierno peronista. Desde mayo de 1952 EL empezó paulatinamente a mostrarse como un diario oficialista, dedicando cada vez mayor espacio a noticias del gobierno nacional y provincial y del partido peronista pero aún sus editoriales seguían ocupándose de cuestiones generales y sin adentrarse en las temáticas tradicionalmente asociadas a la prensa peronista. Luego de la caída del peronismo fue intervenido por el nuevo gobierno (Solís Carnicer, De los Reyes, 2019) 
de la vida política de Corrientes ya que, a través de sus páginas, no solo puede seguirse el ritmo de los acontecimientos del período, sino que por medio de sus editoriales se pueden establecer las representaciones que cada sector partidario construyó sobre sí mismo y sobre sus adversarios.

\section{La etapa final del peronismo: el rol de la Iglesia Católica en la oposición política y frente al golpe de Estado. La situación en la provincia de Corrientes}

A fines de 1954, la tensión entre oficialismo y oposición existente desde principios de la «década peronista» sufrió una importante escalada. El recurso del derrocamiento por la vía de la conspiración militar por parte de los rivales, así como la persecución y prisión a los opositores que llevó a cabo el gobierno, fueron considerados, por ambas partes, herramientas de lucha legítima. La jerarquía de la Iglesia Católica se sumó de lleno a la oposición, lo que generó un vertiginoso crecimiento y ampliación del conflicto. ${ }^{4}$ Esta institución había dado acompañamiento inicial a Perón en 1946, dado que se había visto favorecida con varias medidas en su favor tomadas por el gobierno militar precedente, entre ellas el decreto de enseñanza religiosa en las escuelas públicas, luego ratificada por ley del Congreso. De acuerdo con Loris Zanatta entre los años 1930 y 1943 se constituyó «un bloque político e ideológico antiliberal que giró alrededor de la Iglesia y el Ejército» que facilitó ese acercamiento (Zanatta, 1999: 7).

Sin embargo, para el año 1954 esa relación cordial se revirtió y la Iglesia comenzó a difundir sus preocupaciones por la decadencia de los valores morales y el relajamiento de las costumbres atribuidas al gobierno. Estos temas no eran ajenos a su discurso tradicional, pero tomaron un nuevo cariz en el marco de la confrontación con el peronismo. Por medio de sus publicaciones, desde los púlpitos y en los panfletos que se hicieron circular entre parroquias y colegios católicos se inició una importante campaña de agitación ${ }^{5}$. La Iglesia tenía su propia vocación hegemónica que Perón aspiraba a desplazar y el avance del peronismo sobre aquellos espacios que consideraba propios -tales como la acción social y la educación- fue importante en este distanciamiento, primero, y abierto enfrentamiento, después. Sumado a las críticas por el culto a

\footnotetext{
4. Tcach $(2006,231-234)$ discute la idea de que la Iglesia Católica haya mantenido relaciones armónicas con el gobierno hasta fines de 1954. Analizando el caso de la provincia de Córdoba, señala la existencia de una ofensiva católica desde 1952. Algo similar podría plantearse para el caso correntino, en el que encontramos algunas posturas críticas de la Iglesia o colaboracionistas hacia sectores opositores desde principios de la década de 1950. 5. Muchos de estos panfletos fueron recopilados y publicados en Lafiandra (1955).
} 
la imagen de Perón y Eva Duarte, por la doctrina y la «liturgia» peronista, la sanción de un conjunto de leyes y decretos contrarios a la prédica de la Iglesia católica entre las que se encontraban el divorcio vincular, la autorización de la apertura de establecimientos donde se ejercía la prostitución, la reglamentación del derecho de reunión y prohibición de manifestaciones religiosas en lugares públicos y, finalmente, el anuncio del envío al Congreso de una ley de reforma constitucional para separar la Iglesia del Estado, fueron decisivos para profundizar el conflicto entre ambos sectores (Caimari, 2002: 468). Según José María Ghío (2007), la constitución de un Partido Demócrata Cristiano en julio de 1954 sumó un elemento más al alejamiento de Perón de sus vínculos con la Iglesia al ver los peligros que acarreaba la movilización de los católicos y la organización de carácter transnacional que ella tenía, así como su peso social, legitimador y simbólico. Por otro lado, se ha sostenido que el conflicto desatado entre la Iglesia y el peronismo previo al triunfo de las actividades conspirativas fue mucho más que el enfrentamiento con un gobierno o un partido, se trató además de un conflicto interno que estalló dentro del universo ideal de la «nación católica» sostenida años antes ${ }^{6}$. Por ello señalan Di Stefano y Zanatta que el conflicto trascendió la dimensión política para complicar un nivel mucho más profundo, el de la identidad y la cohesión del catolicismo argentino (Di Stefano y Zanatta, 2000: 461).

En ese contexto la provincia de Corrientes, con una importante presencia católica en su población, no fue ajena a esta disputa aunque no alcanzó el grado de violencia que tuvo en otros espacios ${ }^{7}$. Allí la oposición cuestionó las medidas por las cuales se decidió retirar las imágenes religiosas de las escuelas y oficinas públicas, la supresión de la enseñanza religiosa en las escuelas, de la personería jurídica a diferentes asociaciones religiosas y el levantamiento del feriado del 3 de mayo, día en que se recordaba la fundación de la ciudad y el Milagro de la Cruz (Solís Carnicer, 2017). Considerada una de las fiestas cívico-religiosas más importantes de la ciudad, por primera vez en 1955 no concurrieron representantes del gobierno a la procesión. ${ }^{8}$ El 29 de mayo se

6. Esta interpretación sostenida por Zanatta (1999) sostiene la idea de que la Iglesia contribuyó a forjar el mito de la «nación católica» en su aproximación a las esferas del Ejército en la década de 1930 y derivó posteriormente en una identificación con el peronismo. A partir del triunfo del golpe de Estado de 1943, la Iglesia alcanzaría enormes cuotas de poder, asentada en la colaboración e identificación plena con los gobiernos, por lo menos hasta 1949.

7. Según el censo de 1947, el $98,6 \%$ de la población de la provincia profesaba la religión católica. IV Censo General de la Nación. Población 1947. Tomo 1, p. 216.

8. «La impartición de la enseñanza religiosa en escuelas provinciales dejase sin efecto». $L a$ Mañana, Corrientes, 11 de junio de 1955, p. 5; «Decreto que debería dejarse sin efecto». 
decidió oficiar una misa en la Iglesia Catedral presidida por el obispo y el presbítero Pedro Alarcón, con el propósito de desagraviar a la institución y a sus fieles por las disposiciones adoptadas por el gobierno. Al término de la ceremonia, algunos concurrentes resolvieron realizar una manifestación callejera. La policía se opuso a su realización y algunas personas fueron detenidas. Se trató de importantes dirigentes políticos autonomistas y radicales que habían participado en la manifestación, y del sacerdote que los acompañaba. A todos se les aplicó veinticinco días de arresto insustituibles por multa. ${ }^{9}$ Este suceso, que fue muy comentado en la prensa opositora y oficialista -esta última, desmintiendo los malos tratos denunciados y justificando la actitud policial- motivó un fuerte debate en la Legislatura, en la que los representantes del radicalismo solicitaron informes al Poder Ejecutivo por esas detenciones, pedido que fue denegado por los peronistas (Solís Carnicer, 2017).

Otro momento álgido del conflicto entre la Iglesia y el peronismo se dio durante la celebración de Corpus Christi en Buenos Aires donde a una multitudinaria procesión le siguió un acto vandálico de quema de banderas argentinas, hecho que el gobierno terminó responsabilizando a militantes opositores. En todo el país y también en Corrientes se realizaron diferentes actos de desagravio con una importante participación de personas. Un editorial se publicó en el periódico oficialista $\mathrm{El}$ Liberal refiriéndose al momento:

«El sentir de la correntinidad, pueblo tradicionalmente cristiano, no deja lugar a dudas y así sabrán los malos sacerdotes que no conseguirán embaucarlo con burdas patrañas ni tampoco podrán seguir por mucho tiempo ignorando en los santuarios que fueron costeados por los creyentes para mantener viva la divina lumbre del amor y ellos, intrusos, han convertido en tristes remedos de repugnantes cometidos, nidos de oprobio». ${ }^{10}$

Tal como se señala en el artículo citado, el enfrentamiento entre el peronismo y la Iglesia Católica en Corrientes planteó al mismo tiempo una disputa por la «correntinidad», uno de cuyos rasgos fundamentales se sostenía sobre la profunda religiosidad de su sociedad (Solís Carnicer, 2017).

La Mañana, Corrientes, 22 de julio de 1955, p. 3 y «Magnitud y extraordinaria y rebosante de fervor fue la procesión del día 3». La Mañana. Corrientes, 5 de mayo de 1955, p. 1.

9. Entre los detenidos estuvieron el presidente del PDN, los ex diputados radicales Jorge Luis Picasso y Porfirio Aquino y el sacerdote que había oficiado la misa, Pedro Alarcón. «En el Senado provincial se trató las últimas detenciones». La Mañana, Corrientes, 2 de junio de 1955, p. 1. «Los hombres en las rejas y las señoras en el "Buen Pastor"». La Mañana, Corrientes, 1 de junio de 1955, p. 4. Archivo General de la provincia de Corrientes (AGPC), Corrientes.

10. «El sentir de la correntinidad». El Liberal. Corrientes, 15 de junio de 1955, p. 3. 
El 16 de junio se produjo un fallido intento de golpe de Estado con un trágico bombardeo a la Plaza de Mayo de Buenos Aires y la posterior represalia de los simpatizantes del gobierno con la quema de las iglesias en la ciudad. No sucedió nada similar en Corrientes, aunque existieron sospechas sobre la posibilidad de que se produjera algún hecho semejante con motivo de recordarse un nuevo aniversario de la muerte de Eva Perón el 26 de julio. Por eso, en la noche de la víspera se organizaron diferentes células de personas armadas que se atrincheraron en iglesias y parroquias de la ciudad de Corrientes dispuestas a enfrentar esa probabilidad, pero finalmente nada ocurrió (Harvey, 2011: 215).

Para agosto de 1955, las posiciones entre oficialismo y oposición ya eran irreconciliables. El golpe que se venía preparando desde hacía meses estalló finalmente el 16 de septiembre de 1955. Tras diferentes escaramuzas y enfrentamientos a lo largo del país, la Junta Militar en la que Perón había delegado momentáneamente el poder, firmó el fin de las hostilidades. Luego, esta misma Junta aceptó la renuncia de Perón. Para el 21 de septiembre, se dio a conocer a través de la prensa el derrocamiento del presidente y el cambio de autoridades en cada una de las provincias (Spinelli, 2005: 41).

El 22 de septiembre, el diario La Mañana de Corrientes -propiedad del presidente del partido autonomista- publicó un enorme titular que encabezaba la primera página del diario: «La Caída del tirano» dando a conocer que la Junta Militar de Buenos Aires formada por generales pertenecientes a las fuerzas leales al gobierno de Perón y ante la cual éste declinara sus atributos presidenciales, aceptó los términos de rendición incondicional que le fuera impuesta por el Comando Revolucionario. Además, informaba que por orden de la Junta Provisional del Gobierno de la Nación, el General de Brigada Esteban Font se haría cargo del gobierno de la provincia. Ese mismo día el General Eduardo Lonardi asumió como presidente provisional de la república. Una multitud, en un clima festivo, se congregó en la plaza 25 de mayo de la ciudad de Corrientes, frente al monumento al Gral. San Martín para escuchar su discurso:

«El espectáculo que ofrecía la plaza era en verdad indescriptible: ondear de pañuelos blancos y de banderitas argentinas, brazos en alto que parecía dar gracias a Dios por la felicidad de ser libres, gritos de alegría vivando a la libertad, gente que se abrazaba y se estrechaba la mano, en la comunión espiritual de una misma alegría y de un mismo triunfo. Y las campanas de la Merced lanzadas al vuelo, subrayaban las exclamaciones de la multitud con el tañido de sus bronces, proclamando las glorias de este día de la libertad ... ¡Qué diferencia con los actos a los que nos tenía acostumbrado el régimen! Aquí era el pueblo auténtico el que salía a la calle para expresar su regocijo sin que nadie lo mandara ni lo obligara, y la gente que colmaba la plaza no era llevada 
a la fuerza obligada por el miedo y la amenaza de los mandones. Así celebró

Corrientes el triunfo de la Libertad». ${ }^{11}$

El 24 de septiembre con motivo de celebrarse la festividad de la Virgen de la Merced, el presbítero Alarcón -que había sido detenido luego de los acontecimientos de mayo- dio un fuerte mensaje en su homilía señalando la alegría que representaba para el pueblo y la Iglesia de Corrientes la caída del gobierno peronista «que empezó formulando teorías espléndidas, concretó después cualificaciones magníficas y degeneró más tarde en un sistema asfixiante». ${ }^{12}$

\section{La Iglesia Católica durante el gobierno de la Revolución Libertadora}

Una vez consumado el golpe de Estado y luego de la renuncia de Perón, el General Lonardi -que había liderado la rebelión en Córdoba y que pertenecía a un sector liberal y clerical del Ejército-asumió inmediatamente la presidencia provisional. Sin embargo, su política moderada con respecto al peronismo sintetizada en la frase «ni vencedores, ni vencidos» le trajo inmediatas críticas por parte de los sectores más abiertamente antiperonistas -entre los que se encontraba el vicepresidente, Contraalmirante Isaac Rojas- y muy pronto se vio obligado a renunciar.

Se plantean así dos momentos claves en el recorrido de la autodenominada Revolución Libertadora. En el primero, si bien ambos sectores del gobierno de facto -aquellos más moderados y los más radicalizados en torno a la cuestión peronista- se plantearon como principal objetivo la «desperonización» del país ${ }^{13}$, Lonardi se propuso también el de la «pacificación», por la cual creía

11. La Mañana. Corrientes, 24 de septiembre de 1955, p. 4 y 6.

12. La Mañana. Corrientes, 28 de septiembre de 1955, p. 1.

13. Se denomina desperonización a la respuesta que dio el gobierno de la Libertadora a la pregunta de ¿qué hacer con el peronismo? Se trató de una estrategia de acción política inspirada en la desfascistización y desnazificación. La política de desperonización se inició durante la gestión presidencial de Lonardi pero se acentuó y profundizó durante el gobierno de Aramburu en el que se tomaron medidas que apuntaban más claramente en esa dirección tales como la intervención de la Confederación General del Trabajo, la disolución de la Secretaría de Prensa y Actividades Culturales de la Presidencia y del Partido Peronista con la confiscación de sus bienes, la prohibición de todo tipo de propaganda, incluyendo el pronunciar el nombre propio del presidente depuesto y el de su esposa, la utilización de imágenes, símbolos y signos y la liquidación de la Fundación Eva Perón. Por otra parte, se decretó la degradación de oficiales y suboficiales de las tres armas que habían actuado en defensa del gobierno constitucional derrocado, fueran o no peronistas, la puesta en disponibilidad del personal docente y administrativo de los distintos niveles educativos y se implementaron cláusulas discriminatorias para acceder a cargos o concursos, cesantías en reparticiones de salud pública, en la justicia y en otras dependencias estatales. En ese marco y como forma de justificación de dichas 
importante mantener los beneficios sociales que había ofrecido el peronismo pero sin la presencia de Perón, lo que no fue aceptado por los sectores más radicalizados que exigían del gobierno medidas más duras en el proceso de investigación y castigo a los dirigentes del régimen depuesto. En noviembre de 1955 Lonardi fue reemplazado por el general Pedro Eugenio Aramburu quien imprimió a su gobierno un decisivo rol desperonizador definiendo al peronismo como enemigo del sistema democrático y de la nación misma. La llegada de Aramburu a la presidencia de facto acarrearía el alejamiento definitivo de los cuadros que vieron la posibilidad de retomar algunos postulados considerados positivos del peronismo depuesto, sobre todo lo relacionado a la organización de la clase obrera y los sindicatos. En esta segunda etapa, la tarea de desmontar el aparato peronista no se refirió sólo a la fase investigadora y represiva, sino que fue acompañada de una serie de medidas desde el poder político que tendían a devolver la autonomía de las instituciones y a derogar la legislación centralizadora que el peronismo había utilizado con sus opositores, preparando el camino para el retorno al orden institucional (Tcach, 2003).

El vicepresidente Isaac Rojas -que se mantuvo en el cargo- impulsó la formación de Juntas Consultivas, órganos formados por los partidos opositores al peronismo (con excepción del comunismo que fue excluido a priori) que funcionaron tanto a nivel nacional como en cada una de las provincias. Surgió allí, en el seno de algunos partidos políticos de diverso orden ideológico, un antiperonismo tolerante que empezó a cuestionar algunas de las medidas adoptadas por el gobierno. ${ }^{14}$ Ante la derogación de la Constitución aprobada durante el peronismo, en 1956 comenzó a discutirse una posible reforma constitucional a la que adhirieron un sector de la Unión Cívica Radical, el Partido Demócrata Cristiano, el Partido Socialista, el Partido Demócrata y el Demócrata Progresista. Posteriormente la discusión viró sobre la posibilidad de reformar el sistema electoral y allí nuevamente la opinión se dividió entre quienes estaban a favor del sistema de lista incompleta de la Ley Sáenz Peña de 1912 (fundamentalmente la UCR) y los que preferían un sistema de representación proporcional. Finalmente, este último sistema fue el que se impuso para la elección de Convencionales Constituyentes de 1957. Sin embargo, la

medidas el peronismo, como identidad política, se definió como el enemigo del sistema democrático y de la nación misma». (Spinelli, 2011).

14. Se ubicaban en este grupo los radicales intransigentes que se separaron del tronco de la UCR y provocaron la división del partido en dos, la UCRI y la UCR del Pueblo (UCRP), el partido Conservador Popular en el que se nuclearon algunas facciones de partidos conservadores provinciales entre los cuales estuvo un sector del partido autonomista de Corrientes y la Unión Federal un partido de orientación nacionalista católica. (Spinelli, 2005: 88-89). 
Convención resultó un fracaso luego de que los representantes de la Unión Cívica Radical Intransigente (UCRI) la abandonaran y lo único que se pudo concretar fue el retorno a la Constitución de 1853 con algunos agregados (Spinelli, 2005: 53-128).

En la provincia de Corrientes, después del golpe, el 21 de septiembre de 1955 se hizo cargo de las funciones de Interventor el General Font y pocos días después lo hizo, también en forma interina, el Coronel Oscar Raúl Dumas, para asumir finalmente el titular designado Capitán de Navío y después ascendido a Contraalmirante, Manuel Norman Bianchi, quien se mantuvo en ese cargo hasta el retorno institucional en 1958, lo que marcó una diferencia con las etapas señaladas más arriba en cuanto al gobierno nacional. Todos los partidos políticos actuantes en Corrientes -con excepción del comunismo y del peronismo que se encontraba proscripto- colaboraron con el gobierno formando parte de la Junta Consultiva provincial. En el decreto de su creación a principios de 1956, el interventor federal señalaba entre los considerandos que era «conveniente para la orientación de los problemas de Estado la institución en el orden provincial de un órgano similar al establecido por el gobierno de la Nación, con el objeto de prestar su asesoramiento en los problemas y actividades de toda índole». ${ }^{15} \mathrm{La}$ Junta se constituyó con veinte miembros, cuatro de cada uno de los siguientes partidos políticos: Autonomista, Liberal, Demócrata Progresista, Radical y del recientemente creado Partido Demócrata Cristiano. Además de la Junta Consultiva, a semejanza del plano nacional se organizaron Comisiones Investigadoras para revisar todo lo actuado por el peronismo en la provincia, recibir denuncias de los diferentes sectores e iniciar los procesos judiciales a aquellos funcionarios involucrados en actividades ilícitas (Harvey, 2010). Estas últimas se disolvieron en abril de 1956 luego de la presentación de los respectivos informes que fueron entregados a la Justicia. ${ }^{16}$

Por otro lado, el éxito del golpe de Estado de 1955 trajo esperanzas renovadas para los nacionalistas católicos que se habían distanciado del peronismo, por lo menos hasta el mes de noviembre de ese año, en que estaría al frente del gobierno el General Lonardi. ${ }^{17}$ Durante su breve presidencia se generaron ciertas ilusiones entre las autoridades eclesiásticas que se vieron frustradas

15. El Liberal. Corrientes, 11 de enero de 1956. p 1.

16. El Liberal. 10 de abril de 1956. p 1.

17. Lonardi había nombrado en su gabinete a reconocidos nacionalistas católicos. Clemente Villada Achával y el mayor Guevara como asesores de la presidencia; Mario Amadeo como Ministro de Relaciones Exteriores y Culto; Atilio Dell'Oro Maini como Ministro de Educación; Juan José Uranga como ministro de Transportes; Luis de Pablo Pardo como Ministro del Interior, entre otros. 
al poco tiempo con su reemplazo por Aramburu. En esta segunda etapa, el gobierno de facto fue menos condescendiente con la jerarquía de la Iglesia aunque ella siguió siendo una importante fuente de legitimidad que consideraba al catolicismo uno de los pilares sobre los cuales se había construido la identidad nacional, por lo que debía ocupar un lugar destacado en la arquitectura institucional de la nación. Los ejemplos de acercamiento entre el gobierno y la Iglesia son muchos, desde la supresión de la ley de divorcio sancionada por Perón, el reconocimiento de la enseñanza libre, la creación de doce nuevas diócesis y la institución del obispado castrense. La Iglesia, por su parte, se lanzó a la reconquista de los trabajadores, constituyéndose en un fuerte «factor de poder» (Di Stefano, Zanatta, 2000: 461-465).

En la provincia de Corrientes, la Iglesia Católica se constituyó en un actor central durante todo el período. La permanencia del mismo interventor durante todos los años de gobierno militar colaboró en ese sentido. La Iglesia se involucró directamente en todas las discusiones políticas, sociales y económicas que se plantearon haciendo sentir su voz y marcando sus espacios de poder. Una de las primeras medidas tomadas por la intervención federal fue la devolución de la personería jurídica a todas las asociaciones católicas que las habían perdido durante el enfrentamiento de la Iglesia con el peronismo, señalando que no había motivos para que se les haya privado la personería siendo esas asociaciones «de hondo arraigo en el seno de nuestra sociedad». ${ }^{18}$ La primera gran manifestación de esa mancomunión entre el gobierno y la Iglesia local se dio apenas unos días después del triunfo de la revolución. En el marco de la celebración religiosa de Cristo Rey, se organizó una imponente procesión de antorchas por las principales calles de la ciudad capital presidida por el Obispo Monseñor Francisco Vicentín y por autoridades nacionales y provinciales que culminó con la entonación del Himno Nacional Argentino. ${ }^{19}$ Por otro lado, se involucraron fuertemente en la discusión sobre la libertad de enseñanza, que implicaba la re instauración de la enseñanza religiosa en las escuelas provinciales. Una solicitada publicada por la Acción Católica se refirió con claridad a este tema al señalar:

«Cabe, en primer lugar, a la religión Católica, oficialmente reconocida por todas las Constituciones Argentinas, reclamar el reconocimiento de su derecho divino de enseñar su doctrina a todos los que libremente quieren conocerlo como una concepción de la vida, y a la que, por lo tanto ningún poder humano

18. El Liberal. Corrientes, 11 de octubre de 1955. p. 3.

19. El Liberal. Corrientes, 29 de octubre de 1955. p. 7 y El Liberal. Corrientes, 31 de octubre de 1955 , p. 3. 
puede poner trabas para que sea expuesto en las escuelas en la que se deben impartir todos los conocimientos esenciales para la vida». ${ }^{20}$

Fundamentaban ese pedido además en el «profundo catolicismo del pueblo correntino», considerando que la posición católica era la única que lograba identificarse con sus derechos esenciales. La importancia del catolicismo para la provincia en este período pudo comprobarse también en las multitudinarias asambleas de la Acción Católica que se realizaron en agosto de 1956. Finalmente, al acercarse el momento de las elecciones a convencionales constituyentes la Junta Diocesana de Corrientes con la firma del Obispo hizo llegar a todos los partidos políticos una nota requiriéndoles que respondan un cuestionario sobre la posición del partido en lo relativo al divorcio, la enseñanza religiosa, la libertad de enseñanza, la libertad de sindicalización y la separación de la Iglesia y el Estado. ${ }^{21}$ Esto mismo advirtió el interventor Bianchi en un informe elevado al vice presidente Isaac Rojas en el que señalaba «[... y no olvide que el factor político más ponderable de esta provincia [...] está en la Iglesia» ${ }^{22}$.

Estas iniciativas muestran claramente el peso institucional y social que la Iglesia parecía atribuirse a sí misma en ese contexto. Pero la participación de la Iglesia en la Revolución Libertadora no solo se limitó a la acción de las jerarquías ni a los referentes regionales de su estructura institucional, sino que también mostró otras aristas novedosas: una de ellas fue la creación de agrupaciones políticas plenamente identificadas con el ideario de la democracia cristiana. Diego Mauro (2020) afirma que más allá de las diferentes maneras en que se definió la democracia cristiana, la búsqueda de una vía del medio entre los extremos de la derecha y la izquierda constituyó un rasgo constante de sus principales agrupaciones, tanto desde las experiencias de la Unión Democrática Cristiana (UDC), la Unión Democrática Argentina (UDA), el Partido Popular como la del Partido Demócrata Cristiano en esta etapa que analizamos $^{23}$. Según el autor, hasta la década de 1950, el fortalecimiento de

20. El Liberal. Corrientes, 25 de abril de 1956. p. 2.

21. El Liberal. Corrientes, 20 de julio de 1957. p 3.

22. Carta del interventor Norman Bianchi al Almirante Isaac Rojas, Corrientes 16 de marzo de 1957. Departamento de Estudios Históricos Navales. Archivo personal Almirante Isaac Rojas. Correspondencia oficial, FIFR-DEHN C12.

23. Diego Mauro sostiene que las dos principales tendencias o modelos de democracia cristiana que coexistieron en esas agrupaciones fueron una de impronta «confesional», dominante hasta finales de la década de 1920 y basada en la búsqueda de la convergencia con la Iglesia y sus asociaciones y en sintonía con los postulados "corporativistas» del catolicismo social. La otra tendencia era el sector «secularizado», basado en un mayor grado de diferenciación entre Iglesia, organizaciones católicas y partidos democristianos, 
la democracia cristiana en Argentina no había sido lo suficientemente sólido como para dar lugar al surgimiento de una fuerza electoral capaz de jugar un rol políticamente significativo (comparado con otros casos como Italia, Alemania, Chile o Venezuela ${ }^{24}$. Una de las explicaciones de este derrotero -ensayadas por Mauro, por los mismos actores o la bibliografía militante- hacen énfasis en la oposición de la jerarquía de la Iglesia Católica a tales iniciativas, a la importancia de las corrientes nacional-católicas durante las décadas de 1930 y 1940, o bien al fuerte predominio dentro del sistema político argentino de los dos principales movimientos populares como el radicalismo y el peronismo. Esos partidos no solo dejaron pocos espacios para la incorporación de nuevos actores, sino que contaban con programas cercanos a los principios sostenidos por la democracia cristiana. Además, otros factores esbozados fueron la inestabilidad política del país, signada por constantes golpes de Estado y el difuso contenido de la reforma social católica que dio lugar a repetidos debates y conflictos que estuvieron en la base de los naufragios de muchos de los intentos de convergencia (Mauro, 2020). De modo que la organización de la democracia cristiana encontró en este periodo algunas condiciones favorables: una dictadura cuyos dirigentes estuvieron plenamente identificados con el catolicismo, la proscripción del partido mayoritario y las crisis internas del radicalismo, lo que colaboraría en el surgimiento de nuevas formaciones políticas.

Siguiendo la reconstrucción que nos ofrece Eduardo Ghirardi (1983), los orígenes del Partido Demócrata Cristiano en Argentina se remontan al año 1954. A principios de julio se reunieron algunos dirigentes en la ciudad de Rosario para analizar la posibilidad de formar un partido político de inspiración cristiana, sentar sus bases doctrinarias y un programa de acción. Entre sus principales promotores se encontraban Horacio Sueldo, Oscar Puiggrós, Manuel

caracterizado además por un compromiso más estrecho con la democracia parlamentaria. En este segundo modelo, jugaron un papel clave las concepciones teológicas y políticas de Jacques Maritain y Luigi Sturzo en el plano internacional y los vínculos que tejieron con sectores del catolicismo argentino durante la década de 1930. Estas vinculaciones transnacionales, no exentas de altibajos, se hicieron más firmes tras la segunda posguerra, alimentadas por el giro del Vaticano, el fortalecimiento de las redes católicas antifascistas desde los Estados Unidos y el auge de los partidos democristianos en Europa y América Latina.

24. Scott Mainwaring y Timothy Scully (2010) ofrecen una interesante propuesta analítica para estudiar los objetivos y las estrategias del PDC en Latinoamérica en contextos de autoritarismo con elecciones y de democracias frágiles. Establecen que en ese marco el PDC participa simultáneamente en dos juegos: uno «electoral» cuyo objetivo es ganar votos o escaños y uno de "régimen», en el cual su objetivo es influir en el resultado de conflictos sobre los regímenes políticos. Tal vez por su escaso impacto en la arena política o por algunas de las explicaciones vertidas por Mauro, en esa obra no se ha analizado el caso argentino. 
V. Ordóñez, Juan T. Lewis, Salvador Busacca, Juan José Torres Bas y Carlos J. Llambí, quienes intervinieron en la creación de la llamada Junta Promotora Nacional de Partidos Políticos Provinciales de Inspiración Democrática Cristiana.

Durante los últimos meses del gobierno peronista, ya en pleno conflicto con la Iglesia Católica, la Junta Promotora hizo público un manifiesto titulado «La Democracia Cristiana Argentina al Pueblo y al Gobierno», donde se reprochaba la política oficial, se exponía el núcleo de la doctrina partidaria y se aceptaba la tesis de la pacificación nacional. ${ }^{25}$ Cuando se produjo el golpe de Estado, la Junta Promotora Nacional dio a conocer un segundo manifiesto dirigido «Al pueblo y al Gobierno Provisional», en el cual se criticaba al gobierno depuesto, pero al mismo tiempo se fijaba posición propia frente a quienes accedían al poder.

Con la llegada del nuevo gobierno de facto, los dirigentes de la democracia cristiana comenzaron a participar activamente en él, para el 15 de noviembre Manuel V. Ordoñez y Rodolfo Martínez (h) pasaron a formar parte de la Junta Consultiva Nacional y los esfuerzos se centraron en la organización partidaria. En diciembre se reunió en la ciudad de Córdoba una Convención Nacional que dio a conocer una declaración de Principios, redactó una Carta Orgánica Federalista, adoptó un Programa, fijó un distintivo -la Punta de Lanza Roja sobre Cuña Azul-y designó a la primera Junta Nacional. Además, se arbitraron los medios para participar en el Congreso Internacional Demócrata Cristiano en Santiago de Chile en el que asistieron como delegados argentinos Manuel Ordóñez y Salvador Busacca.

A principios de enero de 1956 la noticia de la conformación de este nuevo partido se publicó en la prensa de Corrientes. Sus dirigentes señalaron que continuarían colaborando con el gobierno de la Revolución Libertadora en la medida que ésta mantuviera una línea democrática y popular y que el partido retiraría el apoyo al gobierno en aquellas provincias en las que consideraban se habían desvirtuado los fines revolucionarios. Asimismo, elevaron una protesta por las cesantías indiscriminadas que se habían llevado a cabo y resolvieron luchar por la libertad de enseñanza y la indisolubilidad del matrimonio. En

25. En resumidas líneas, el comunicado afirmaba lo siguiente: «La Democracia Cristiana parte de la naturaleza del hombre. El hombre es lo único eterno de la creación: todo pasará, él no pasará nunca. Por ello es el centro de todo: Estado, sociedad, familia, escuela, economía, sindicato, están a su servicio. No hay régimen posible, no sólo humano, ni siquiera civilizado, si se ruega al hombre el acceso a la verdad o se le coarta libertad para conseguir la justicia. La libertad es una e indivisible [...] Ni libertad para morirse de hambre ni justicia que beneficie a una parte sola del pueblo», (Ghirardi, 1983: 87-88). 
otros pasajes de la declaración solicitaron al gobierno la adopción de medidas urgentes para mejorar el nivel de vida de los habitantes, detener los desalojos urbanos y rurales y estudiar los convenios colectivos de trabajo. ${ }^{26} \mathrm{Al}$ final del documento señalaron su postura respecto del contexto político:

«Denunciar públicamente la actitud de grupos totalitarios en todas sus formas, que a fin de justificar su fracasado intento de desvirtuar la revolución para restablecer la dictadura, están reincidiendo en un viejo maquiavelismo de la difamación política y en la pretensión de aprovechar el sentimiento religioso argentino para crear conflictos artificiales con la Iglesia». ${ }^{27}$

Según Ghirardi, pese a la unidad de acción que se mostraba a la sociedad, los demócratas cristianos desde el principio estuvieron atravesados por distintas tendencias internas que iban desde el apoyo al liberalismo económico y político a ultranza hasta su completa oposición, y con diferentes posturas frente al peronismo (Ghirardi, 1983: 91). Desde el partido se crearon Centros de Estudio, se realizaron actos callejeros, se auspició el Primer Congreso Agrario -en un intento por abrir su radio de acción a los productores rurales no latifundistas-, se opusieron a los proyectos de ley de divorcio, reclamaron las paritarias, se preocuparon por la carrera de precios y salarios y cuestionaron las cesantías indiscriminadas a trabajadores como resultado de actos de revanchismo contra el peronismo. En agosto de 1957 y en el marco de las discusiones sobre la reforma del sistema electoral, dieron a conocer un documento en el que reclamaron el mantenimiento del sistema de representación proporcional que se había utilizado para las elecciones de convencionales constituyentes de ese año:

«Por razones de justicia y de conveniencia para el bien general de la Nación que necesita liberarse del falso esquema político de dos únicos partidos que se alternaban o se cambian en el poder, privando el acceso a otras corrientes que hoy suman más de dos millones de ciudadanos sin contar los votos que no tienen partido». ${ }^{28}$

Asimismo, planteaban con claridad el lugar que ellos consideraban le correspondía en el espectro político del país. Se ubicaron en el espacio «nacional y popular de revolución social» diferenciándose tanto de los radicales como de los conservadores y de los nacionalistas.

26. La Junta Ejecutiva Nacional fue conformada por dirigentes de diferentes provincias: Lucas F. Ayarragaray, como presidente, Juan Lewis como secretario, José Carlos Ricci como tesorero, Angélica Fuselli, Manuel Ordoñez, Guillermo López, Francisco Cerro, Ricardo Marcelo Dussel, Carlos Imbaud y José Alejandro Miler como vocales. El Liberal. Corrientes, 2 de enero de 1956. p. 2.

27. El Liberal. Corrientes, 22 de diciembre de 1955. p. 2.

28. El Liberal. Corrientes, 22 de agosto de 1957. p. 2. 


\section{La democracia cristiana en Corrientes: orígenes, dirigentes y discursos}

Unos días después del triunfo de la denominada Revolución Libertadora, a principios de octubre de 1955 se constituyó la Junta Promotora Provincial del PDC en Corrientes. La integraron figuras íntimamente ligadas a la militancia católica especialmente de la Acción Católica entre los que se encontraban el reconocido abogado y allegado al Arzobispado Emilio Kairuz, Ernesto del Mei, Jorge Giménez Dixon y David Romero Garate. En su primera declaración pública buscaron posicionar al partido en un espacio de regeneración política que enlazaba las tradiciones más destacadas de la provincia con las banderas levantadas por el nuevo gobierno:

«En este momento trascendental del país en que un terrible fragor de sangre rompió la cortina de la tiranía y aparecen la paz y la libertad tanto tiempo anhelados, nuestra valiente provincia guaraní -bastión legendaria de la libertad-no puede quedar en la zaga ante la única solución propuesta para recuperar la dignidad de la Patria y establecer los derechos de la Argentinidad». ${ }^{29}$

A partir de allí se inició el proceso de organización del partido a través de la realización de diferentes actividades que incluyeron la circulación de dirigentes nacionales. El primer acto público se llevó a cabo con motivo de la visita de Carlos Juan Llambí, integrante de la Junta Nacional que dio una conferencia en Corrientes a principios de noviembre de 1955 en la que explicó la doctrina y los objetivos del partido centrados en la «reconstrucción de la Nación, fundada en la verdad, la justicia y el amor cristiano». ${ }^{30}$ En el mismo acto también hicieron uso de la palabra Emilio Kairuz por la Junta Promotora Local y María Fagúndez que formaba parte de la rama femenina del partido en Buenos Aires. Posteriormente, se organizaron una serie de cursillos dictados en diferentes lugares de la ciudad con el propósito de hacer conocer los principios partidarios. Algunos de los temas que se abordaron en dichos cursos giraron en torno a «La Democracia Cristiana y los problemas presentes» $\mathrm{y}$ «La dignidad de la persona humana», entre otros. ${ }^{31}$ Asimismo, empezó a editarse Democracia Cristiana, que se convirtió en el órgano de difusión del partido en la provincia. ${ }^{32}$ En términos del polítólogo italiano Angelo Panebianco (1993) la etapa de formación de un partido es crucial para la determinación de sus rasgos organizativos. En este caso resulta de interés señalar el momento particular en el cual la democracia

29. «Constituyóse la Junta Provincial del Partido Demócrata Cristiano». La Mañana. Corrientes, 8 de octubre de 1955. p. 5.

30. El Liberal. Corrientes, 4 de noviembre de 1955. p2.

31. El Liberal. Corrientes, 30 de noviembre de 1955. p 2.

32. El Liberal. Corrientes, 24 de diciembre de 1955. p 2. 
cristiana se formó en la provincia, durante el gobierno de la «Libertadora» y estando el peronismo proscripto. En ese contexto intentó captar a un sector de los votantes peronistas a través un discurso que dejaba notar cierta cercanía ideológica con aquel partido aunque remarcando su carácter cristiano y cercano a la Iglesia Católica con la cual el peronismo se había distanciado en la última etapa de su gobierno.

El 14 de noviembre dio inicio la apertura de la afiliación para lo cual se habilitaron diferentes sedes en la ciudad capital. En un manifiesto señalaron que podía inscribirse cualquier ciudadano argentino que reuniera los siguientes requisitos: «1) Adhesión a la Declaración de principios del partido; 2) Presentar solicitud de afiliación; 3) No haber sido dirigente político durante los últimos seis meses y 4) Gozar de buena fama». ${ }^{33}$ Paralelamente, participaron activamente del espacio radial «La Hora de los Partidos» que se difundía por LT7 Radio provincia de Corrientes todos los días a las 23 horas y en el que tenían abiertos los micrófonos todos los partidos políticos actuantes en ese momento en la provincia, con excepción del peronismo y el comunismo. El PDC, a pesar de ser un partido de reciente formación participó asiduamente de ese espacio en el que abordaron cuestiones tales como «La democracia cristiana y el momento actual», «La reforma agraria a la luz de la democracia cristiana», «La vivienda», «Razones y motivos de la actuación de la mujer en la política», «La familia, segundo principio fundamental de la Democracia Cristiana», «La economía humanista», «La responsabilidad de los padres en la educación de sus hijos», «La libertad de enseñanza», «La misión de la Democracia Cristiana en el trabajo», entre otros ${ }^{34}$ A mediados de diciembre de 1955 cinco representantes locales del partido participaron de la Convención Nacional que se reunió en Córdoba y adhirieron a los documentos que allí se aprobaron. A principios de abril de 1956 se llevó a cabo en la plaza Cabral de la ciudad de Corrientes el primer acto público de relevancia del PDC en la provincia con la presencia de dirigentes nacionales, locales y de las provincias vecinas. ${ }^{35}$ Finalmente obtuvo su personería jurídica en enero de 1957 y avanzó su conformación en todo el interior provincial constituyendo Juntas Departamentales. ${ }^{36}$

En varias provincias (como San Luis o Chaco), el partido le quitó colaboración al gobierno cuestionando su posición parcial y con favoritismos hacia ciertos sectores políticos, situación que no ocurrió en Corrientes. Sin embargo,

33. El Liberal. Corrientes, 14 de noviembre de 1955. p 2.

34. Los diarios locales informaban diariamente sobre estas conferencias, a veces con alguna semblanza de los expositores.

35. El Liberal. Corrientes, 9 de abril de 1956. p. 2.

36. El Liberal. Corrientes, 23 de enero de 1957. p. 2. 
en abril de 1957, luego de haberse conocido las fechas en las que se realizarían las elecciones nacionales y provinciales consideraron $-\mathrm{y}$ así lo hicieron saber al interventor- que la existencia de una Junta Consultiva había dejado de tener sentido motivo por el cual solicitaron su disolución y presentaron sus renuncias a la misma sus representantes. ${ }^{37}$

A lo largo de los dos años y ocho meses del gobierno de la Libertadora en varias oportunidades se pronunciaron sobre diferentes temas que formaban parte de sus principios doctrinarios. En primer lugar, como partido de alcance nacional debieron diferenciarse de las otras agrupaciones que se reivindicaban cristianas pero con una fuerte orientación nacionalista, como la Unión Federal Demócrata Cristiana a la que acusaron de querer «sacar provecho del sentimiento religioso popular de la Iglesia», pero al mismo tiempo se mostraron distantes de los «viejos partidos inficionados del liberalismo caduco» ${ }^{38}$ y del comunismo "por ser el régimen que ofrece el mayor peligro y las más grave amenaza para el mundo contemporáneo» ya que entre éste y la doctrina cristiana creían que existía una oposición «esencial e irreductible». ${ }^{39}$

Por otra parte, en numerosas ocasiones se manifestaron a favor de los obreros y de los sectores más vulnerables de la sociedad señalando la importancia de solucionar esos problemas que consideraban fundamentales: «reclamamos que el capital cambie de procedimientos, no se puede dar coces contra el aguijón, ni se puede nadar contra la corriente. Estamos en el principio de una de las más grandes revoluciones de la historia: la revolución por la justicia del trabajo»..$^{40}$ Asimismo, reclamaban con insistencia la constitución de comisiones paritarias, reorganizar los sindicatos a través de elecciones internas libres y darle urgente tratamiento a la cuestión obrera a fin de conseguir la paz social. ${ }^{41}$ Se consideraban representantes del pueblo trabajador y preocupados por su situación económica ante el retraso de los salarios en relación al aumento del costo de vida. ${ }^{42}$ Frente a esto, en muchas ocasiones elevaron sus reclamos al gobierno tanto nacional como provincial. Lo mismo puede decirse sobre el problema de la falta de viviendas, cuestión que consideraron crucial, de primera necesidad y de urgente solución. ${ }^{43}$

37. El Liberal. Corrientes, 5 de abril de 1957. p. 2.

38. El Liberal. Corrientes, 18 de octubre de 1956. p. 2.

39. El Liberal. Corrientes, 2 de octubre de 1956. p. 2.

40. El Liberal. Corrientes, 2 de julio de 1956. p 6.

41. «La Democracia Cristiana ante la situación obrera del país». El Liberal. Corrientes, 1 de diciembre de 1956. p 2.

42. El Liberal. Corrientes, 30 de abril de 1956. p. 2

43. El Liberal. Corrientes, 16 de abril de 1956. p 2. 
El problema agrario fue otra de sus constantes preocupaciones, para lo cual plantearon la necesidad de una reforma agraria integral que abarcara todos los aspectos de la vida rural. ${ }^{44}$ Estas propuestas, esbozadas en una provincia como Corrientes con una economía tradicional y con predominio del latifundismo, resultaban novedosas para el discurso político local a pesar de los avances que en materia de derechos habían conseguido los trabajadores rurales durante el peronismo ${ }^{45}$. En el mismo sentido puede mencionarse la posición que adoptaron frente a las cesantías indiscriminadas en la administración pública motivadas por cuestiones políticas. Muy importante fue la campaña que llevaron adelante en Corrientes, a la que se sumó el mismo obispado, para conseguir la reincorporación de docentes cesanteados sin previo sumario consiguiendo que se revirtiera la medida. ${ }^{46}$ Consideraban un acto de injusticia inaceptable el privar del trabajo a una persona como consecuencia de las ideas políticas que ésta hubiera defendido, planteando que debía asegurarse la estabilidad y escalafón de los maestros y empleados nacionales, provinciales y municipales. Señalaban que era parte de la doctrina cristiana evitar el revanchismo pues éste iba en contra del mandato planteado por «Jesucristo de amar a los enemigos y hacer el bien a los que los odian». ${ }^{47}$

Por otro lado, dentro del discurso defendido por el PDC correntino también aparecen inquietudes asociadas a la idea de la familia fundada en el «matrimonio monogámico e indisoluble que encuentra su plena realización en la filiación legítima». De acuerdo con esta concepción era también la familia la encargada de la procreación y de la educación de la prole. ${ }^{48}$ Por ello, se opusieron con firmeza a la decisión del gobierno nacional de reimplantar la Ley 1420 por la cual se había aprobado la enseñanza laica. El argumento con el cual plantearon su oposición a esta medida fue el considerar que la educación era exclusiva responsabilidad de los padres y que eran ellos y no el Estado, los que debían decidir acerca de la educación religiosa de sus hijos. Planteaban que la enseñanza religiosa debía ser optativa en todas las escuelas públicas pues consideraban que el laicismo había causado un grave perjuicio moral y espiritual a la Patria, descristianizándola, sentenciando que «no se puede concebir que en Argentina, hija dilecta de la civilización cristiana se piense, se obre y se

44. El Liberal. Corrientes, 9 de junio de 1956. p 2.

45. A partir de la sanción del Estatuto del peón rural en 1944 se había iniciado un proceso de transformación del mundo rural de la provincia pero dichos cambios se dieron de manera pausada y eran apenas incipientes para 1955 (Solís Carnicer, 2019).

46. El Liberal. Corrientes, 10 de abril de 1956. p 2.

47. El Liberal. Corrientes, 29 de marzo de 1956. p 2

48. El Liberal. Corrientes, 12 de septiembre de 1957. 2. 
viva con una concepción atea y materialista de la vida». ${ }^{49}$ Se consideraban el partido que representaba más cabalmente los rasgos de la identidad nacional a la que asociaron con los principios de la civilización occidental y cristiana. Por otra parte, se presentaron como un partido nuevo alejado de los rasgos más tradicionales y conservadores de los partidos autonomista y liberal de Corrientes y del liberalismo pregonado por el partido radical.

Si bien eran conscientes de sus limitaciones electorales, dieron a conocer los resultados exitosos que las experiencias de gobierno de la democracia cristiana habían conseguido en otros países como una forma de demostrar las capacidades que el partido podía desplegar si llegaba al gobierno. ${ }^{50}$ En vistas de las elecciones generales para reorganizar los poderes del Estado, en diciembre de 1957 se reunió en la ciudad de Goya una Convención provincial del partido para considerar la plataforma electoral, fijar la línea política a seguir y elegir los candidatos a gobernador y vice de la provincia, diputados nacionales, senadores y diputados provinciales. ${ }^{51}$ La fórmula gubernativa quedó conformada con Carlos Alberto Speroni y Nicolás Francisco Liotti, que pertenecían a la línea liberal católica del partido (Marturet, 2018: 49). La campaña electoral fue intensa y los resultados fueron positivos si se tiene en cuenta que fue su primera participación en una elección provincial, el partido obtuvo 11.705 votos lo que le permitió contar con dos electores en el Colegio Electoral que debía elegir al futuro gobernador y dos diputados en la legislatura provincial. ${ }^{52}$ Los electores de la UCRI y del Partido Conservador Popular votaron por la fórmula de la UCRI consiguiendo de ese modo la mayoría necesaria para consagrar a Fernando Piragine Niveyro y Félix María Gómez como gobernador y vice de Corrientes. El día antes de la reunión de la Asamblea, el PDC emitió un comunicado en el que señalaron que sus electores votarían únicamente por su fórmula pero ofrecieron su colaboración a quienes resultasen electos pidiendo para ellos «la fecunda y permanente bendición de Dios, fuente de toda razón y justicia». ${ }^{53}$

49. El Liberal. Corrientes, 20 de marzo de 1956. p 2.

50. «Comunicado». El Liberal, Corrientes, 19 de abril de 1956. P. 2.

51. Participaron de la Convención representantes de todas las Juntas Departamentales de la provincia y se contó además, con la presencia del candidato a presidente Lucas Ayarragaray. El Liberal. Corrientes, 7 de diciembre de 1957. p 2.

52. Quedó en quinto lugar detrás de la UCRI, del Partido Conservador Popular (ex autonomista), del Partido Liberal y de la UCRP.

53. El Liberal. Corrientes, 17 de marzo de 1958. p 3. 


\section{Conclusiones}

A partir de la llegada de los militares al poder tras el golpe de Estado en 1955 en Argentina, se abrió un nuevo panorama para el heterogéneo conglomerado de actores sociales y políticos que se habían pronunciado contra el régimen peronista. Para los sectores católicos, la Revolución Libertadora no solo había conjurado el «peligro» que le disputaba el campo político y social y limitaba sus aspiraciones de expansión, sino que significó el inicio de una época fecunda en discusiones, debates, iniciativas y posibilidades reales de participación política.

La participación del catolicismo en el contexto de la dictadura se dio en diferentes dimensiones y niveles. Por un lado, vemos que el apoyo explícito de la jerarquía de la Iglesia al golpe contribuyó a su legitimidad y su influencia ha sido observada en el plano discursivo e ideológico y en la recuperación del espacio público. Por otro lado, se dio la colaboración de sus cuadros dirigentes en la estructura del gobierno de facto y el surgimiento y organización de agrupaciones políticas, como el PDC, que por primera vez lograron alcanzar cierta competitividad electoral.

Sin embargo, pese al apoyo explícito a la dictadura y a las diferentes tendencias internas que los atravesaron, hemos observado cómo los demócratas cristianos en diferentes momentos intentaron diferenciarse de las iniciativas más fervientemente antiperonistas del gobierno de la Libertadora, haciendo un llamado a la tolerancia y a la convivencia. La experiencia del PDC sorprendió en varios sentidos. En primer lugar, por la rapidez en que logró organizarse y dotarse de una estructura con cierta presencia territorial, tal como sucedió en la provincia de Corrientes. En segundo lugar, los vínculos construidos con referentes regionales y trasnacionales, aportaron una impronta novedosa frente a la propuesta de los partidos mayoritarios de alcance nacional. Finalmente, el análisis del caso del PDC correntino nos permitió comprender de qué manera logró un partido de reciente constitución insertarse y diferenciarse en un sistema político provincial con rasgos marcadamente tradicionales. Combinó en su discurso elementos que hacían referencia a esas tradiciones arraigadas en el ideario católico -relacionados con el mantenimiento de la familia como una unidad primordial y la defensa de la educación religiosa- con otros nuevos como aquellas propuestas relativas al mejoramiento de las condiciones materiales de los trabajadores o la reforma agraria. Pese a los resultados electorales obtenidos, puede decirse que los votos cosechados demuestran que los demócratas cristianos lograron -en poco tiempo- constituirse en una de las preferencias de los ciudadanos correntinos en el proceso de transición democrática ofreciendo una nueva vertiente de canalización de los intereses sociales a través de un partido que logró combinar exitosamente los rasgos más 
tradicionales de la sociedad provincial -como su ferviente catolicismo- con los propios del nuevo contexto ideológico que se planteaba hacia mediados del siglo $\mathrm{XX}$.

\section{Bibliografía}

CAIMARI, Lila (2002). El peronismo y la Iglesia Católica. En Juan Carlos TORRE (Dir.) Nueva Historia Argentina. Los años peronistas (1943-1955) (441-479). Buenos Aires: Sudamericana.

CASTILLO, Fernando (2014). El partido demócrata cristiano en Jujuy durante la Revolución Libertadora: tensiones, trayectorias y representaciones. E-l@tina. Revista electrónica de estudios latinoamericanos, 13, (49), octubre- diciembre. Buenos Aires: Instituto de Investigaciones Gino Germani.1-15. https://publicaciones.sociales.uba.ar/index.php/elatina/article/view/586/523

DI STEFANO, Roberto, ZANATTA, Loris (2000). Historia de la Iglesia Argentina. Desde la Conquista hasta fines del siglo XX. Buenos Aires: Grijalbo-Mondadori. FERNÁNDEZ, Sandra (2007). Los estudios de historia regional y local: de la base territorial a la perspectiva teórico-metodológica. En Sandra FERNANDEZ. Más allá del territorio: la historia regional y local como problema. Discusiones, balances y proyecciones, (31-45). Rosario: Prohistoria Ediciones.

GHÍO, José María (2007). La Iglesia Católica Argentina. Buenos Aires: Prometeo.

GHIRARDI, Enrique (1983). La democracia cristiana. Buenos Aires: Centro Editor de América Latina.

HARVEY, Ricardo (2010). Breve Historia de la provincia de Corrientes desde 1930 a 2001. Corrientes: Universidad de la Cuenca del Plata.

HARVEY, Ricardo (2011). Historia política contemporánea de Corrientes. 1949-1955. Corrientes: Moglia Ediciones.

LAFANDRIA, Félix (h) (1955). Los panfletos, su aporte a la Revolución Libertadora. Buenos Aires: Itinerarium.

MAINWARING, Scott (2010). Objetivos de partido en regímenes autoritarios con elecciones o en democracias frágiles: un doble juego. En: Scott MAINWARING, Timothy SCULLY La democracia cristiana en América Latina. Conflictos y competencia electoral (19-54). México: Fondo de Cultura Económica.

MARTURET, Mario Alfredo (2018). Diputado... iyo? Corrientes: Moglia ediciones. MAURO, Diego (2020). La democracia cristiana en Argentina. Formaciones políticas, partidos y vínculos transnacionales (1912-1967). Revista Ayer, 118, 2, 133-161. http://revistaayer.com/articulo/1414

PANEBIANCO, Ángelo (1993). Modelos de partido, organización y poder en los partidos políticos. Madrid: Alianza. https://doi.org/10.22201/ fcpys.2448492xe.1994.157.49873 
SOLÍS CARNICER, María del Mar (2017). La «Revolución Libertadora» en la provincia de Corrientes. Los partidos políticos, la Iglesia y el Ejército frente al golpe de 1955. Quinto Sol. Revista de Historia, 3, (21). Instituto de Estudios Sociohistóricos, Facultad de Ciencias Sociales, UNLPam, septiembre-diciembre, 1-27. https://cerac.unlpam.edu.ar/index.php/quintosol/article/view/1129 SOLÍS CARNICER, María del Mar (2019). «Los trabajadores en litigio. Una aproximación al mundo del trabajo rural en Corrientes a mediados del siglo XX a partir de fuentes judiciales.» En: Cuyonomics. Investigaciones en Economía Regional. Universidad Nacional de Cuyo. Año 2, N. ${ }^{\circ} 4$, segundo semestre de 2019, pp 58-85. https://doi.org/10.19137/qs.v21i3.1129

SOLÍS CARNICER, María del Mar, DE LOS REYES, Andrea (2019). Prensa y política en la Argentina peronista. Un análisis de las prácticas periodísticas en un espacio provincial marginal (Corrientes, 1945-1955). Estudios del ISHiR, 23, Investigaciones Socio Históricas Regionales, Unidad Ejecutora en Red -CONICET, 1-25. https://ojs.rosario-conicet.gov.ar/index.php/revistaISHIR/ article/view/909

SPINELLI, María Estela (2005). Los vencedores vencidos. El antiperonismo y la «Revolución Libertadora». Buenos Aires: Biblos.

SPINELLI, María Estela (2011). La desperonización: una estrategia política de amplio alcance (1955-1958). Programa Interuniversitario de Historia Política. http://historiapolitica.com/datos/biblioteca/Spinellil.pdf

TCACH, César (1994). Partidos y pactos políticos en la Córdoba Libertadora (1955-1958). Revista Estudios, 3. Córdoba: Centro de Estudios Avanzados de la Universidad Nacional de Córdoba, Argentina.17-30.

TCACH, César (2003). Golpes, proscripciones y partidos políticos. En Daniel JAMES (Dir.) Nueva Historia Argentina. Violencia, proscripción y autoritarismo (18-61). Buenos Aires: Sudamericana.

TCACH, Cesar (2006). Sabattinismo y peronismo. Partidos políticos en Córdoba. Buenos Aires: Sudamericana.

ZANATTA, Loris (1999). Perón y el mito de la «Nación católica». Iglesia y Ejército en los orígenes del peronismo. 1943-1946. Buenos Aires: Sudamericana. 